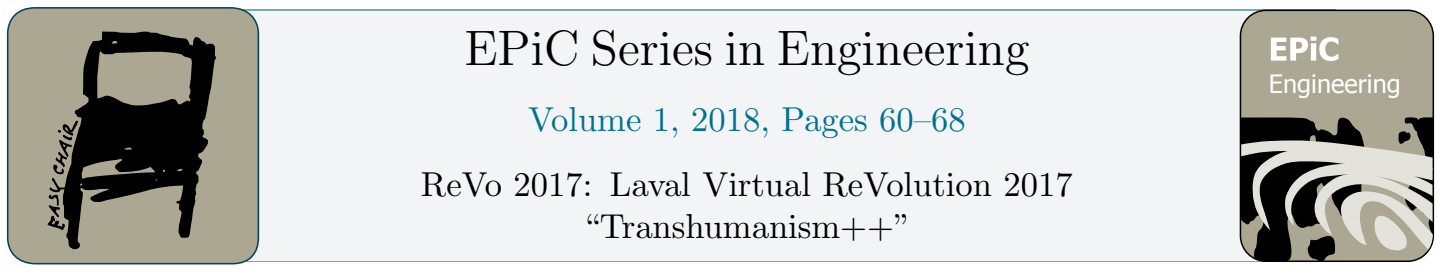

\title{
Superhuman Sports Games in Laval Virtual
}

\author{
Ryoichi Ando ${ }^{1}$ \\ ralgaap@gmail.com,
}

Hirohiko Hayakawa ${ }^{1}$

h.hayakawa@kmd.keio.ac.jp

\author{
Mai Orikasa ${ }^{1}$ \\ myxhula@gmail.com
}

Kosuke Sato ${ }^{2}$

kosuke@,vrlab.esys.tsukuba.ac.jp

\author{
Minato Takeda ${ }^{1}$ \\ mnttkd@gmail.com
}

\section{Kouta Minamizawa ${ }^{1}$ \\ kouta@kmd.keio.ac.jp

\begin{abstract}
Masahiko Inami ${ }^{4}$ inami@,inami.info
\end{abstract}

1 - Keio University Graduate School of Media Design 4-1-1 Hiyoshi Kohoku-ku Yokohama-city Kanagawa, Japan

2 - School of Integrative and Global Majors (SIGMA) Ph.D. Program in Empowerment Informatics, Univ. Tsukuba1-1-1 tennodai Tsukuba, Japan

3 - Research institute of Sports Facility 5-2-6-403, Minaminagasaki, Toshimaku, Tokyo, Japan 1710052

4 - Research Center for Advanced Science and Technology, University of Tokyo 4-6-1 Komaba, Meguro, Tokyo, Japan 153-0041

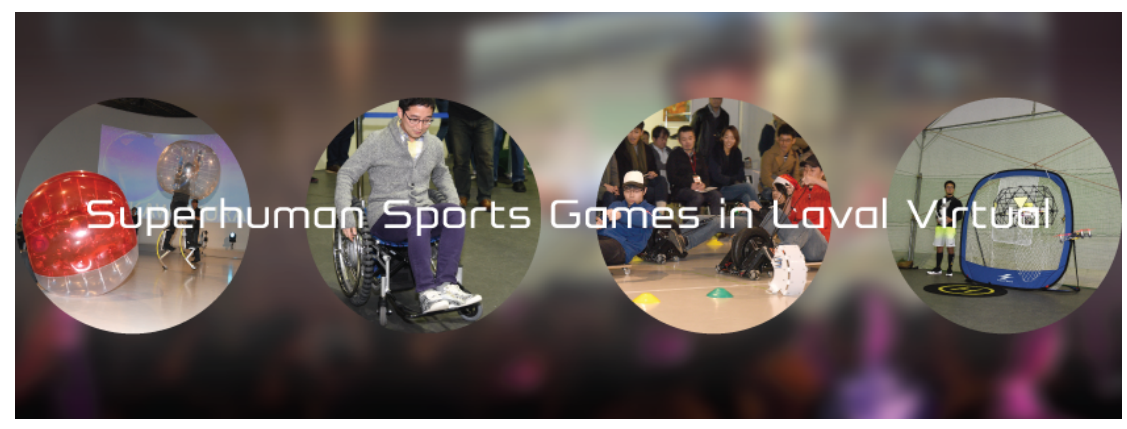

HD Movie Online URL https://www.youtube.com/watch?v=iJrenZvSZjc\&vl=en 


\begin{abstract}
We propose to organize a Superhuman Sports Games ${ }^{1}$ in Laval Virtual. Superhuman Sports is a new form of sports based on the human-machine integration technology that provides new experiences by augmenting our body. Through superhuman sports experiences, people can realize what when our body and machine integrate naturally, human can overcome individual physical differences, and simultaneously, people can believe human can exceed our physical limitations. For this event, we prepared 3 games to provide physical augmentation experiences. Bubble Jumper augments our jumping function and shock absorption function without using any motors, Sli-de-rift adds new foot function with assist motor and Omni wheels, and Carry Otto augments running with in wheel motor.
\end{abstract}

\title{
CCS CONCEPTS
}

- Human-centered computing Interaction design theory, concepts and paradigms - Humancentered computing $\sim$ mixed / augmented reality $\bullet$ Human-centered computing $\sim$ Virtual reality

\section{KEYWORDS}

Superhuman Sports, Human Augmentation, Welfare Engineering

\section{Introduction}

Towards 2020, Tokyo Olympic \& Paralympic, we propose the concept of Superhuman Sports that applied VR, AR, Human Augmentation and such technologies with sports.

To implement this concept as a new culture, Superhuman Sports Society has launched in June, 2015.

This society includes wide range of professionals such as scientist, sports player, designer, artist, and entrepreneur. It purposes for to overcome boundaries, for instance age, sexuality, and such individual differences, and to overstep human's physical limitation, by adapting technologies and cultures for field of sports. For those believes that we mentioned above, this society promises superhuman sports should be everyone can enjoy playing it, everyone can enjoy observing it, and developing continuously. And not just only saying it, the society practicing developer support, player support, and scientist support. Because of those supporting system, now the society can work with not only public people, but also with academics, the government and the markets.

Currently, 12 of superhuman sports games, applied AR, VR, and human augmentation technologies include robotics, are being published on official website of Superhuman Sports Society ${ }^{2}$. Those official games have been authorized by the Society's requirements ${ }^{3}$ to assist developer communities' activity more efficiently. In fact, the authorization system brings for high performance of superhuman sports society's supporting activity that we described before. So far, the superhuman sports society organize the system of creation circuit with people, from sports creation - social application activity amplifying - until monetize it.

(C) 2017 Copyright held by the owner/author(s)

${ }^{1} \mathrm{http}: / /$ superhuman-sports.org/games/

${ }^{2} \mathrm{http}: / /$ superhuman-sports.org/

${ }^{3}$ Name, Photo, Abstract, HP or Official movie available on web, Developer's Information, Developers list, Rule, Technology, Human-Machine Integration 


\section{Definition and Requirement of Superhuman Sports}

When those new sports fulfilled designated requirements that suggested by superhuman sports society, it is permitted as an official superhuman sports. Especially Human-Machine Integration and Sportification put priority to permit as the official game.

\section{Human-Machine Integration}

When technologies are adapted user's will freely, superhuman sports people call the phenomenon as "Jizai"4. Then if augmented human can work with Jizai, we can call the situation as Human-Machine Integrated or "Zinki-Ittai" in Japanese.

\section{Sportification}

When the Human-Machine Integration is assigned to physical activity which well-designed as a sports, Superhuman sports society can call it superhuman sports. But it's not such an easy way to achieve it. For that, the society required to possess scheme to support it, as an organization which keenly support those challenges with wide range of people.

\section{Superhuman Sports Creation}

\subsection{Requirement for Sports Creation}

We held 3 official superhuman sports creation event per year. Based on researches, for instance AJingshu, Bart, and Wim (2014), examined the relationship between open innovation and the financial performance of R\&D project, Francesco, Livio, and Michele (2014), mentioned about the possibility of common culture making by Open Innovation, and Esteve, Melissa, and Ann (2014), studied about civic open innovation by examined with six cities, we set enumerate following fundamentals which required to realize superhuman sports creation by work with developer communities. Those games and the developer communities are developing really keenly and uniquely.

\section{1 $\quad 1^{\text {ST }}$ Superhuman Sports Hackathon}

In July 2015, we held $1^{\text {st }}$ superhuman sports ideation and hackathon to make new superhuman sports. It held at Keio University Hiyoshi Campus on $4^{\text {th }}$ July, 2015 with 83 attendees (Figure 1), and $25^{\text {th }}$ $26^{\text {th }}$ July, 2015 with 47 attendees. (Figure2)

And finally it emerged 14 ideas and 8 game creator's communities. Especially Team BJ, made a game which just combined tools available from the market, called "Bubble Jumper" awarded as the first prize, and Carry Otto developer Team, build a game that applied new original tools build only for this event, called "Carry Otto", and Hover Crosse developer Team made a game, "Hover Crosse" utilized available tools and original tools, played a huge role in after superhuman sports society's activity. After authorizing selection held in $7^{\text {th }}$, July 2016, above 3 of new superhuman sports were authorized by the society.

\footnotetext{
${ }^{4}$ One if the society's co-founder Masahiko Inami put forwarded this idea
} 


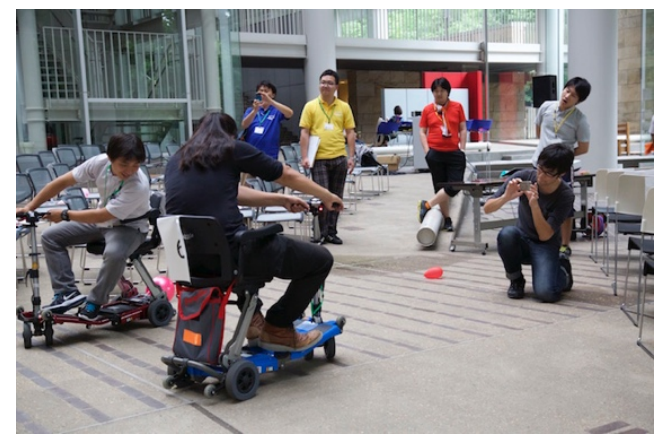

Figure 1: Ideation

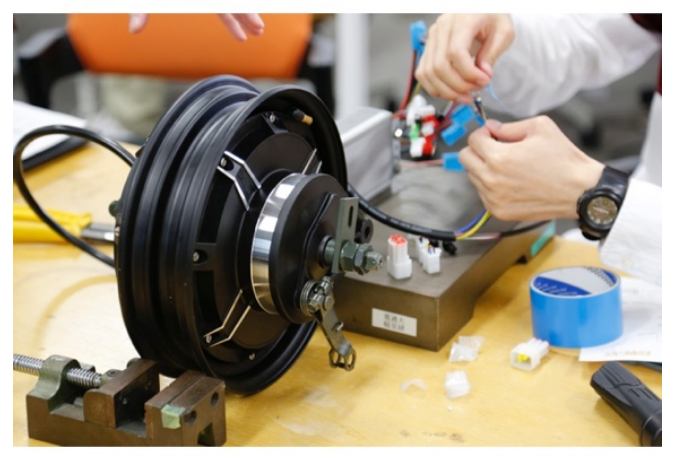

Figure 2: Hackathon

\subsubsection{Bubble Jumper}

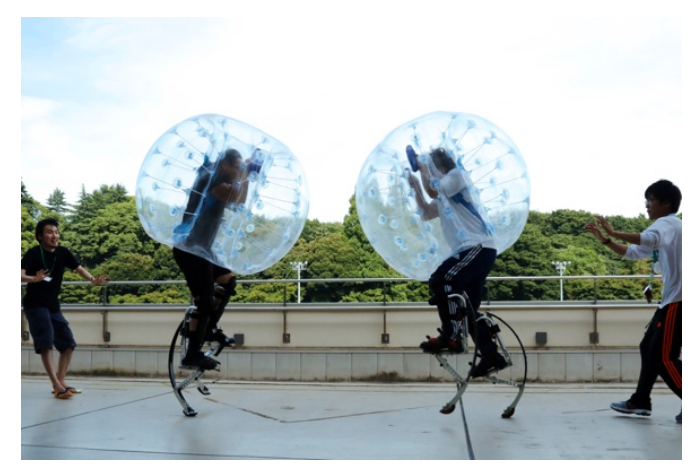

Figure 3: Bubble Jumper

Bubble Jumper (Figure 3) is a restring like sports, stems from Japanese restring like physical activity, Sumo. It can realize augmented action with pair of wearable foot strengthening devices with impact absorption bumper. Now developer team expanding games, from the one-on-one Sumo-like game to a high jump-like game. 


\subsubsection{Hover Crosse}

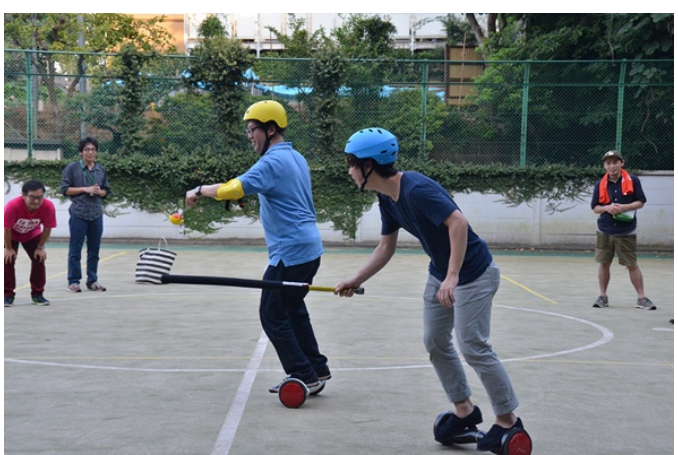

Figure 4: Hover Crosse

Hover Cross (Figure4) uses hand free personal motilities which can operate only by weight shift to play the game. Hover Cross is new for one-on-one sports. Two players are divided into offense and defense, and they compete on the number of balls put into three allotted goals on the field.

Now developer team try to make with visiting designer to make it more looks like futuristic (Figure5).
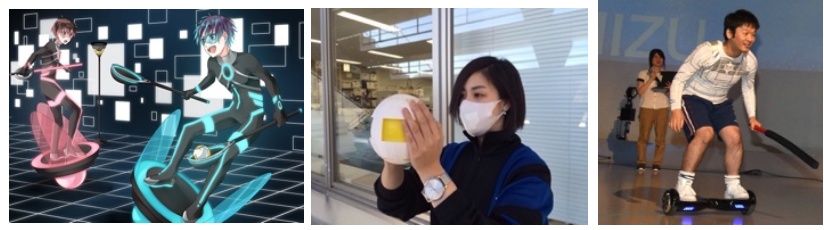

Figure 5: Future Model and Current Process

\subsubsection{Carry Otto}

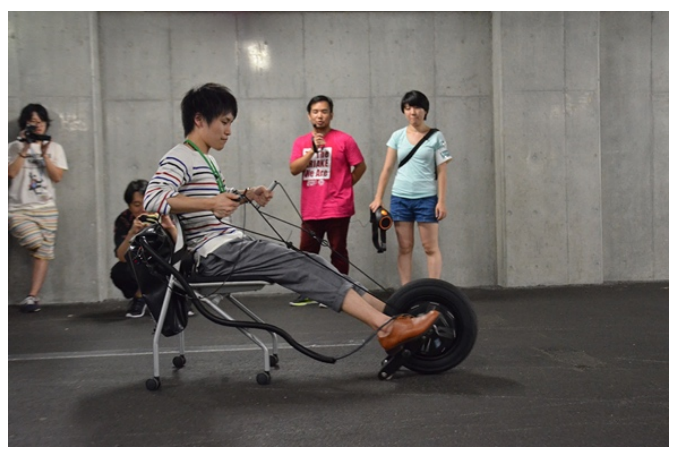

Figure 6: Carry Otto

Carry Otto (Figure6) is a racing game. It stems from ancient history, chariot races, enthused many people. But in Carry Otto, hose replaced by a motor device, Carry Otto is a superhuman sport in which players compete by handling a driving device. Not only depending on physical strength, it requires a relationship between the player and the machine in order to win. 
Now, it achieved 1 million JPY crowd founding under the society's support. And currently, developers are organizing practice event and held workshop to make Original sheets independently (Figure7).
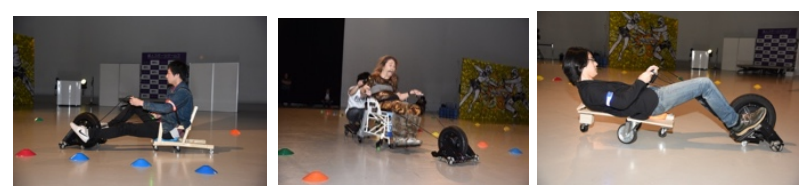

Figure 7: Original Sheets

\section{Superhuman Sports as Welfare Engineering}

Superhuman sports added new point of view in welfare engineer's field. For instance, superhuman sports can make it possible that handicapped people can enjoy sports more vigorously. As examples, we introduce 2 games emerged from $3^{\text {rd }}$ hackathon that we held at July, 2016.

After the $3^{\text {rd }}$ hackathon, both of 2 sports gone their unique process.

As those reasons and facts that we illustrated above, we can say human augmentation technology is applicable for community making even with physically differenced people.

\subsubsection{Sli-de-rift}

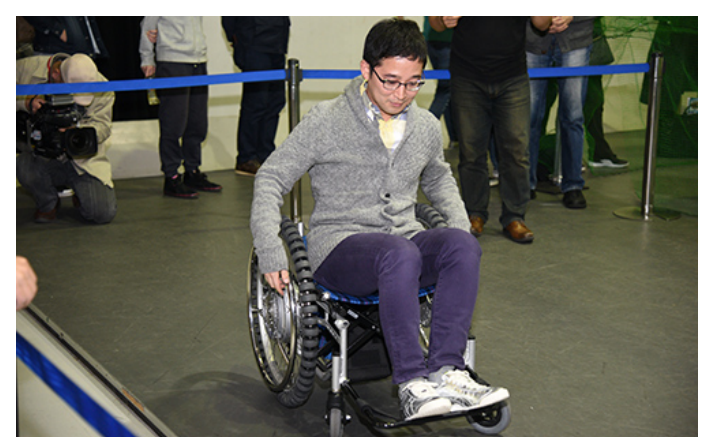

Figure 8: Sli-de-rift

Sli-de-rift is a canoe like game. Player use wheel chair which customized to move like drift by using huge Omni wheel, and try to go through markers which installed in the course. Score is calculated by speed of rap time, and how many markers player checked. It made for create new device which everyone enjoys brand new experience that human couldn't. Developers started to work with visual designer to illustrate this game easier to understand even for people who didn't know, to fix developers concept, everyone can enjoy this game, more concretely. (Figure9)

In November, 2016, this game played by huge number of people that include handicapped, and testified its universalness. (Figure10) 


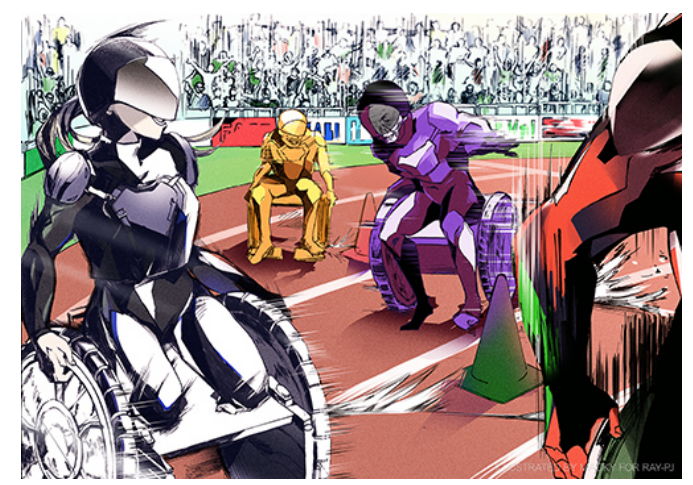

\section{Figure 9: Concept Image}

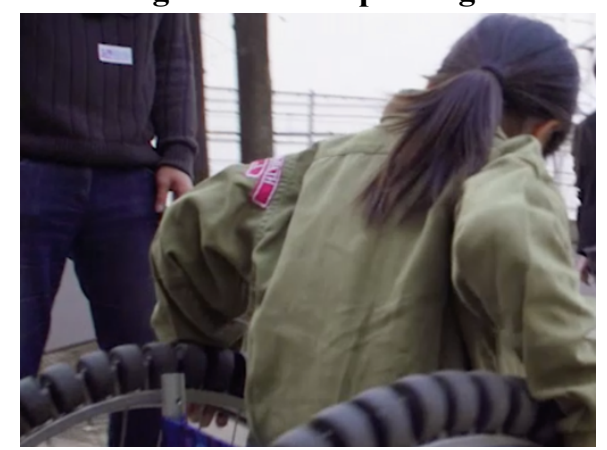

Figure 10: Super welfare expo

\section{Superhuman Sports with Local Culture}

\subsection{Superhuman Sports Project in Iwate}

To testify the possibility that superhuman sports can reutilize cultures, the society held a long term event in Iwate prefecture, Japan.

Iwate is one of a prefecture of Japan where located on Northeast area, and elected as a place where hold national sports event in 2016, for that, the society and Iwate had held sports creation events to set the mood for it by 5 times(Figure10).

Since cultures are usually really complicated, and sometime it stems from hidden official history, we put long term, and put multiple event to make new games with cultures.

Kick off Meeting had held on 24 ${ }^{\text {th }}$ April, 2016, with 115 attendees, Ideation workshop had held on $28^{\text {th }}$. May, 2016, with 38 attendees, hackathon had held on $25^{\text {th }}-26^{\text {th }}$, June, 2016, with 27 attendees, preparation day for the final presentation had held on $20^{\text {th }}$, August, 2016, with 22 attendees, and the Final presentation had held on $24^{\text {th }}-25^{\text {th }}$, September, 2016, with 38 attendees.

This event originated 6 ideas and 4 game creator's communities.

Especially "Battle of the rockhand", build by Battle of the rockhand developer Team, has roots from Iwate Prefecture's history of birth. What makes it more brilliant is those games developers didn't only focus on making new technology integrated sports, but also they researched local shrine and famous novel author who bone in Iwate to create culture based new technology integrated sports. 


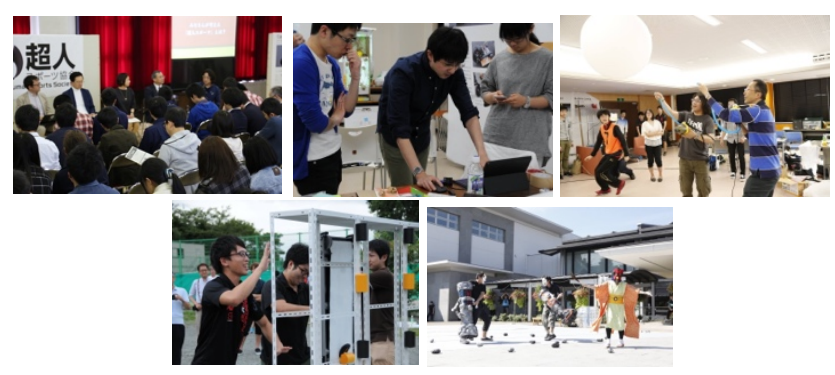

Figure 10: Superhuman Sports Project in Iwate

\subsubsection{Battle of the rockhand (Figure11)}

\section{Figure 11: Battle of the Rockhand}

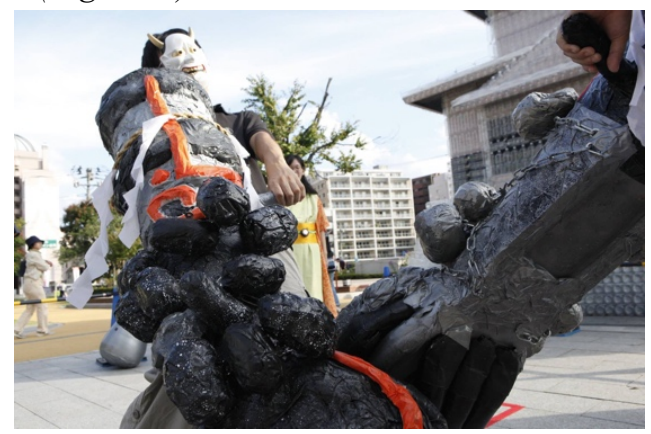

Battle of the rockhand is a battle game. Players waring huge wearable arm to hit each other.

Those arm modules which players wear, molded rock shape, have roots from Iwate prefecture's folktale. And the largest reason that we said it culture based games is this game develops with comic which developers' drawing at the same time.

\section{Superhuman Sports Games}

It is really important that the society cultivate not only developers, but also players and observers, we prepared observable, and able to compete event as a tournament games.

For that, we decided to hold superhuman sports tournament with 4 representative matured games, and public experience of 6 representative newborn games at the same time, to provide same place to celebrate and to support superhuman sports developers' and players' activity at: Tokyo Tower Media Center, Tokyo on $23^{\text {rd }}$, November, 2016 (Figure12). 

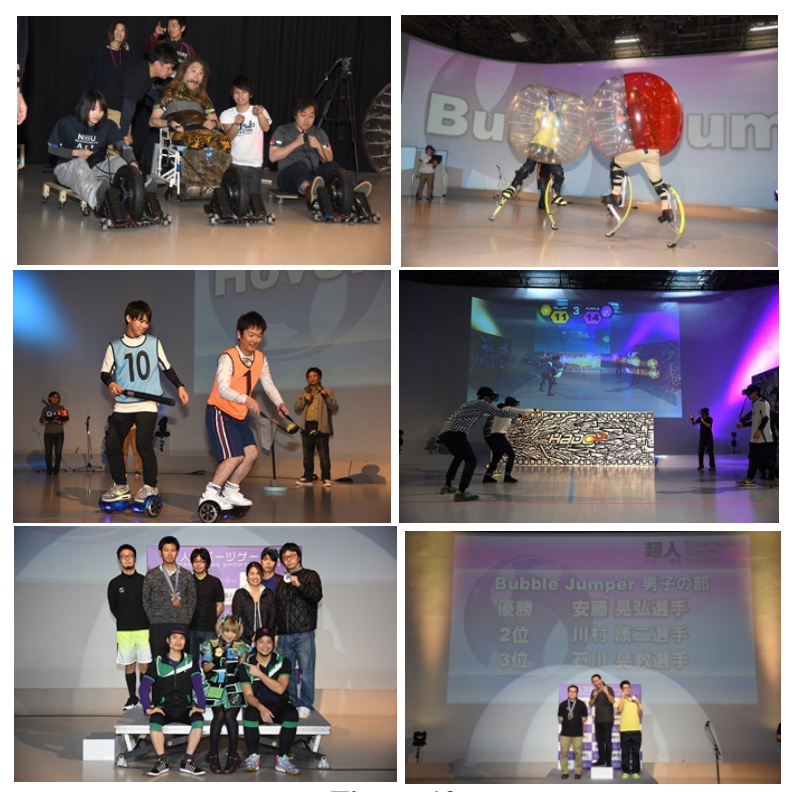

Figure 12

This event courses strong impact for developers and players. For instance, some players began to gather the other player subjectively to make this event more enjoyable for observer and themselves. And all games began to develop their games more enthusiastically for this event. Additionally, they recruited players to know where should be remedied to make their games better.

\section{Conclusion}

As we illustrated through this paper, "superhuman sports" has a possibility to create new public welfare and new cultures. And we want to launch such sports culture from Japan to around the world, to begin with Laval, France.

\section{References}

Jingshu Du, Bart Leten, and Wim Vanhaverbeke. 2014. Managing open innovation projects with science-based and market -based partners Research Policy 43, 5 (June. 2014), 828-840.

DOI: http://dx.doi.org/10.1016/j.respol.2013.12.008

Jingshu Du, Bart Leten, and Wim Vanhaverbeke. 2014. Managing open innovation projects with science-based and market -based partners Research Policy 43, 5 (June. 2014), 828-840.

DOI: http://dx.doi.org/10.1016/j.respol.2013.12.008

Esteve Almirall, Melissa Lee, and Ann Majchrzak. 2014. Open innovation requires integrated competition-community ecosystems: Lessons learned from civic open innovation. Business Horizons 57, 3 (May-June. 2014), 391-400. DOI: http://dx.doi.org/10.1016/j.bushor.2013.12.009 